\title{
Global van Hiele (GVH) Questionnaire as a Tool for Mapping Knowledge and Understanding of Plane and Solid Geometry
}

\author{
PATKIN, Dorit \\ Mathematics Department, Kibbutzim College of Education Technology and the Arts, \\ 13 Dakar Street, Beit Yanai, Israel; Email: patkin@ netvision.net.il
}

(Received December 3, 2013; Revised December 7, 2013; Accepted June 27, 2014)

\begin{abstract}
This paper presents the Global van Hiele $(\mathrm{GVH})$ questionnaire as a tool for mapping knowledge and understanding of plane and solid geometry. The questionnaire facilitates identification of the respondents' mastery of the first three levels of thinking according to van Hiele theory with regard to key geometrical topics. Teachereducators can apply this questionnaire for checking preliminary knowledge of mathematics teaching candidates or pre-service teachers. Moreover, it can be used when planning a course or granting exemption from studying in basic geometry courses. The questionnaire can also serve high school mathematics teachers who are interested in exposing their students to multiple-choice questions in geometry.
\end{abstract}

Keywords: van Hiele theory, Global van Hiele Questionnaire, levels of thinking in geometry, triangles and quadrilaterals, circle, solids, pre-service mathematics teachers, inservice mathematics teachers MESC Classification: B52, B54, B55, B59, G42, G43, G44, G45, G49

MSC2010 Classification: 97B50, 97G40

\section{INTRODUCTION AND THEORETICAL BACKGROUND}

Mathematics educators have been familiar with various versions of the van Hiele questionnaire (Senk \& Usiskin, 1983; Patkin, 1990, 2010; Patkin \& Levenberg, 2004). Designing the expanded questionnaire which is presented in this paper stemmed from the need to expose pre-service teachers to levels of thinking in geometry in a variety of topics. Based on my teaching experience I have realised that mathematics teachers as well as college and university lecturers should identify their students' levels of thinking prior to the course in geometry for students as well as for pre-service teachers and adapt the teaching level to the level of the learners. According to this approach there is a chance of promot- 
ing the levels of thinking of most learners. Herein resides the high importance of this tool.

\section{Van Hiele theory and hierarchical model}

The van Hiele theory was developed by the couple Pierre Marie van Hiele and Dina van Hiele-Geldof at the end of the 1950s (van Hiele, 1959; 1987). The theory aims to explain why many learners and pre-service teachers encounter difficulties in performing higher order cognitive processes, mainly when they have to cope with proofs. This theory advocates that partial mastery of a certain level is a prerequisite but insufficient condition for mastering a higher level. Learners cannot function and be at a certain level if they are not versed in all the previous levels. Learners who have not mastered the first levels yet manage to deal with problems which are typical of an advanced level are referred to as 'inconsistent'. It is important to point out that learners can simultaneously be at different levels from the point of view of different topics and concepts. For example, a learner may be at the third level regarding the topic of quadrilaterals whereas as far as the topic of circle is concerned he/she is only at the first level.

The hierarchical development was described by the van Hieles by means of five levels:
a. recognition or visualisation;
b. analysis or description;
c. order or informal deduction;
d. formal deduction; and
e. rigour.

Mathematics educators, including the van Hieles themselves, have experienced doubts about the existence of the five above-mentioned levels (van Hiele, 1987; Patkin, 1990; Teppo, 1991; Gutierrez, 1992; Cohen, 2007; Patkin \& Barkai, in press). Hence, it is common today to relate to four levels only. The first three levels remain unchanged whereas the fourth and fifth levels have been joined together.

Below is a detailed description of the levels:

Level I: Recognition or visualisation: at this initial level learners can identify geometric shapes and distinguish between them. Each of the concepts or the shapes is perceived as a whole, in the way it is seen. Learners are capable of distinguishing between similar shapes as well as name them. At this level, learners are unable to specify the properties of those shapes. For example: they do not relate to the specific properties of rectangles and to the relation between them and other quadrilaterals (for example, they do not know that rectangle diagonals are equal or that the rectangle has four right angles).

Level II: Analysis or description: at this level learners can analyse properties of shapes but are unable to attribute properties of a particular item to the properties of the group to 
which it belongs. For example: learners know that the opposite sides of a rectangle are equal or that the diagonals of a rectangle have the same length. However they cannot infer from it about some of the square's properties. Learners are unable to deduct that also in a square, being a special rectangle; the diagonals are equal whereas in a parallelogram they are not equal.

Level III: Order or informal deduction: at this level learners identify a hierarchical order of connection between groups of different shapes according to their properties and definitions. However, at this level, they are incapable of proving claims related to the properties of the geometric shapes. For example: at this level learners understand the relationship of connection between a rectangle and a square - every square is a rectangle but not every rectangle is a square. At this level learners are still unable to prove that the diagonals of a rectangle are the same.

Level IV: Formal deduction and rigour: at this level learners understand the roles of basic concepts, axioms, definitions, theorems and proofs and their interrelations. They can use assumptions in order to prove theorems and understand the meaning of necessary and sufficient conditions. At this level learners are able to provide reasons and arguments for the various levels of the proving process. Moreover, they comprehend the importance of discussing the proofs, the deduction from the particular to the general and even the need for a proof of any kind (Patkin \& Levenberg, 2010).

The van Hiele model of levels of thinking in geometry had a strong impact for the past 50 years. During the 1960 s, the theory was used in the Soviet Union in order to adapt the curriculum in geometry to this model (Pyshkalo, 1968). In the United States, this theory was vigorously promoted by Wirzup (1976) who presented the model to mathematics educators. Wirzup's article which presented breakthroughs in the psychology of geometry learning and teaching raised further interest in this model. His descriptions of the van Hiele theory and the successful teaching and learning grounded in it motivated American educators in the 1970s to develop activities according to this theory. The first activity was writing a geometry textbook according to the guidelines of the theory (Hoffer, 1979). At the same time, a collection of activities for teachers was initiated, aiming to identity the learners' level of thinking in geometry as well as attempting to promote them to higher levels (Hoffer, 1983). The van Hiele model was reinforced in 1984, when key parts of the van Hieles Ph.D. thesis were translated from Dutch to English (Geddes, 1981; Fuys \& Tischler, 1985).

\section{Properties of the model}

Van Hiele (Crowley, 1987 in Patkin, 1990) presented five properties of the model: Se- 
quential, advancement, intrinsic and extrinsic, linguistics and mismatch.

Sequential: similarly to most models which engage in development, one should pass through the levels in a sequence. In order to succeed at a certain level, the strategies of previous levels should first be acquired.

Advancement: progress from one level to another depends more on contents and teaching methods than on age. The teaching methods should ascertain that learners do not skip or omit one level. Some of the teaching methods stimulate the progress and reinforce it whereas others delay or even prevent progress between two levels.

Intrinsic and extrinsic: "a concept which was intrinsic is embedded in one level" (Crowley, 1987, p. 4 - free translation), i.e. a concept studied at a certain level 'from above' and generally speaking becomes the topic of study at the next level. For example: at the first level of van Hiele's theory, the general matrix of the geometric shape is studied while at the second level the shape is already defined according to its properties and components.

Linguistics: Each level has its own linguistic symbols which characterise it. At the first level the symbols are very simple and at higher levels the symbols are more complicated. For example: a square is the simplest linguistic symbol assigned to a regular quadrilateral. However, the names rectangle which is also a rhombus or a rhombus which is also a rectangle matches the definition of a square. Only learners who are at the third level (order and informal deduction) can understand it while learners who are at lower levels encounter difficulties in understanding it.

Mismatch: learners who are at a certain level will find it difficult to understand contents and vocabulary typical of higher levels. Hence, it will be difficult for them to monitor the processes which transpire at the high level. In order to comprehend the contents and the processes of the higher level, one should first understand and master all the contents and all linguistic symbols typical of their level.

The van Hiele theory, unlike that of Piaget (1969), is based on the assumption that moving from one level of thinking to another depends more on experience and teaching than on age or biological maturity of learners (Geddes, Fuys, Lovett \& Tischler, 1982; van Hiele, 1999). This induced Hoffer (1981) to define five basic skill areas which greatly determine the extent of succeeding to enhance the learners' levels of thinking. Consequently, at each level, attention should be paid to the development of these skills. These basic skills are: visual skills, verbal skills, logical skills, drawing skills and applied skills.

Visual skills: geometry is an area the learning of which entails recognition and observation. Thus, it requires developing and implementing visual competence. Learners, whose recognition and observation skills are insufficiently developed, might face difficulties in 
learning.

Verbal skills: in learning subjects in general and in geometry in particular the place of language is most essential either for formulating assumptions, theorems, definitions and describing shapes or for presenting relationships between shapes and so on. The language is mainly used for a uniform and concise formulation in order to achieve maximum accuracy. Learners who have reading comprehension problems or verbal formulation and communication might encounter difficulties in learning geometry.

Logical skills: when learning geometry, learners are required to have logical and reasoning skills. For example: by building claims in a hierarchical manner, one learns to ground claims in arguments, recognise valid and non-valid arguments and discern between a reason and conclusion. Inability to discern between reasons and conclusions and the inability to identify valid arguments might render the solution of geometrical problems rather difficult.

Drawing skills: for the study of geometry, more than for many other subjects, learners need drawing skills in order to understand properties of shapes as well as relationships between geometric shapes for making proofs.

Applied skills: applicability: geometry is a theoretical model of the physical world around us. There are mutual relations between understanding the surroundings and comprehending geometry. One can apply what is learnt in geometry lessons to the surrounding world and one can draw from the world in order to understand geometry. Inability to make this application could disrupt the learning of this subject.

\section{Studies of various geometry topics conducted following the van Hiele theo- ry}

The van Hieles related in their theory only to plane geometry and focused on the topic of triangles and quadrilaterals. Over the years the theory was adopted to additional branches of mathematics as well as to solid geometry (Gutierrez, 1992; Patkin, 2010; Patkin \& Sarfaty, 2012) and arithmetics (Crowley, 1987; Guberman, 2008). Patkin \& Sarfaty (2012) conducted a study which explored whether focused activities (intervention programme) can promote pre-service mathematics teachers' mastery of advanced levels of thinking in solid geometry and improve the way they feel about this area of knowledge. The study showed that learners' level of thinking in geometry can indeed be enhanced, inducing a more positive attitude towards geometry.

One of the most updated studies which investigated the mastery of levels of thinking of pre-service elementary school mathematics teachers was conducted by Patkin \& Barkai (in press). The study checked the mastery of levels of thinking in three major topics: tri- 
angles and quadrilaterals, circle and solids. The study was performed at different points during the pre-service teachers' professional education. The research findings illustrate that the levels of thinking of pre-service teachers in their third year of studies are similar to those in their fourth year and to those of teachers studying for their M.Ed. The learners' levels of thinking in their first year of education and of academicians changing their career to elementary school mathematics teachers were the lowest. Mastery of the level of thinking regarding triangles and quadrilaterals in each of the five groups of research participants was higher than in the case of the other two topics, i.e., circle and solids (Patkin $\&$ Barkai, in press). $43 \%$ of the in-service and pre-service elementary school mathematics teachers are versed in the third level of thinking regarding the topic of triangles and quadrilaterals. The percentage of those versed in the third level regarding the topic of circle is lower (32\%). All the research participants demonstrated lack of mastery in the two higher levels of thinking regarding solids $(0 \%) .25 \%$ of the participants are versed in the first level of thinking. $44 \%$ have not mastered even the first level whereas the rest were diagnosed as 'inconsistent' in their mastery of the levels of thinking.

\section{Design of the questionnaire and its validation for determining levels of thinking in geometry}

At the beginning of the 1980s a questionnaire designed to determine levels of thinking in solid geometry was built and validated within the framework of the CDASSG project performed at the University of Chicago, headed by Usiskin (1982). Some of the questions were formulated in an indirect way and others by way of elimination, requiring logical skills. Giving correct answers to this type of questions indicates verbal and logical skills typical of those versed in high levels of thinking. This is in line with the van Hiele theory and its characteristics. Usiskin (1982) and Senk $(1983,1985)$ validated the questionnaire and the existence of hierarchy between the four levels. Moreover, they found that it is a good predictor of both attainments and the ability to make geometrical proofs (Senk \& Usiskin, 1983). The questionnaire consisted of 25 questions, so that every five questions represented one level in a hierarchical order, from the easy to the difficult. The time allocated by the writers for responding to the questionnaire was about 30-35 minutes. Based on the study of Senk \& Usiskin (1983), the criterion 'three out of five' was determined, namely if learners respond correctly to at least three questions which represent a certain level, that means they have mastered this level. A stricter criterion suggested was 'four out of five', namely if learners respond to at least four questions, they are versed in this level. Furthermore, this research framework defined that learners versed in the first level at the most are 'weak learners'; those versed in the second or third level are 'average learners' while 'strong learners' are those who have mastered the two highest levels 
(fourth and fifth levels). It is important to point out that the researchers' questionnaire comprised questions which related to the topic of triangles and quadrilaterals (Senk \& Usiskin, 1983).

During the 1980s the questionnaire was translated into several versions and it was used by additional researchers (Patkin, 1985; Reingold, 1986; Tepper, 1986; Friedlander, 1988). At the end of the 1980s, in a study which investigated comprehension of concepts at different levels of thinking, a questionnaire was processed in a version relating to hierarchical development of understanding within a framework of four levels only (Patkin, 1990). The study replaced the last ten questions (the five original questions representing the fourth level and the five questions representing the fifth level) by five questions relevant to the contents learnt according to the curriculum in Israel. This was done in a way which represents the extended fourth level (the level representing the two highest levels which are called the 'formal deduction and rigour' level). Due to the decrease in the number of questions (from 25 to 20) the time for responding to the questionnaire was adjusted, namely 25 minutes. The test reliability was calculated according to the TESSOT programme (Levi, 1969) and was 0.82 . The content validity of all the items of the questionnaire including the additional questions was done by five judges, all of them researchers in the field of mathematics education. The judges were required to classify the items into the different levels of the van Hiele theory and indicate items which were irrelevant or which did not meet the appropriate criteria. Moreover, the judges were asked to point out erroneous formulation which could have prevented the learners from understanding the question. When less than four judges concurred about certain assertions, these assertions were removed and replaced by other suitable ones. Furthermore, at the beginning of the 21st century, based on the questionnaire which engaged in triangles and quadrilaterals, Patkin \& Levenberg (2004) conceived a questionnaire with 20 questions (representing four levels of thinking) about the topics of circle and proportion. The questionnaire reliability was 0.85 and it was also validated by four expert judges in a process similar to the one applied in the case of the previous questionnaire. The questionnaire relating to solids (Patkin, 2010) which comprised 15 questions (representing the first three levels of van Hiele theory) was also validated and its reliability was 0.87. Consequently, the questionnaire presented in the appendix has been entirely validated as required.

\section{Using Global van Hiele (GVH) Questionnaire as a tool for identifying the level of knowledge and understanding of geometry}

The Global van Hiele (GVH) questionnaire integrates the three questionnaires which have been formulated separately (for each of the topics: triangles and quadrilaterals, circle and solids). It examines only the first three levels of thinking according to the van Hiele 
theory (Patkin, 1990; Patkin, 2010; Patkin \& Levenberg, 2004). The questionnaire consists of 45 close-ended questions about these topics which are studied in accordance with the curriculum at elementary and junior high schools.

As mentioned above, van Hiele argues that a prerequisite for mastering the highest level of thinking (the fourth level) is mastering the three previous levels. Hence, it is essential to map at the beginning of teacher mathematics education the learners' knowledge and their mastery of the first three levels of thinking. Thus, during their pre-service teacher education, students can master the fourth level of thinking which is the highest. The topics of geometry studies included in the elementary school curriculum (Ministry of Education, Culture and Sport, 2006) relate to the level of teaching the subject while being aware of the van Hiele theory. During the first two years at school, i.e., the $1^{\text {st }}$ and $2^{\text {nd }}$ grades, teaching should comply with the teaching which is typical of the first level; in the $3^{\text {rd }}$ and $4^{\text {th }}$ grades it should match the second level while in the $5^{\text {th }}$ and $6^{\text {th }}$ grades we should strive to make learners master the third level of thinking. The junior high school mathematics curriculum is also based on the hierarchical inculcation of geometry. Being versed in the fourth level, the highest, characterises learners who study mathematics in a more advanced and thorough way (e.g., learners in advanced mathematics classes or university students of mathematics). It is, therefore, important already at the beginning of higher education studies to identify the students' mastery of the three levels of thinking in geometry and train them to attain mastery of the higher levels during their academic studies.

The Global van Hiele questionnaire consists of multiple-choice questions with five optional answers. The respondents have to choose the only correct option. The 45 questions presented in the questionnaire are divided into 15 solid geometry questions associated with solids and 30 plane geometry questions, half of them (15 questions) dealing with triangles and quadrilaterals and the other half (15 questions) about a circle. In each group, every five out of 15 questions represent a separate level of thinking in a rising order of difficulty (five questions at the first level, five questions at the second level and five questions at the third level (See Appendix A).

Below is an exact structure of the questionnaire:

a. Five questions at the first level about the topic of triangles and quadrilaterals (questions $1-5$ ) followed by five questions at the first level dealing with a circle (questions 6-10) and five questions at the first level about the topic of solids (questions 11-15).

b. Five questions at the second level of thinking associated with each of the three topics (questions 16-20 about triangles and quadrilaterals, questions 21-25 about a circle and questions $26-30$ about solids). 
c. A group of 15 questions at the third level dealing with the same topics (questions 31-35 about triangles and quadrilaterals, questions 36-40 about a circle and questions 41-45 about solids).

The time allocated for responding to the questionnaire is $45-60$ minutes. The recommended time framework is based on the time allocated in the original questionnaire and on the time given in the questionnaires developed later (Usiskin, 1982; Senk, 1983; Senk, 1985; Patkin, 1990; Patkin, 2010; Patkin \& Levenberg, 2004).

\section{Recommendation for advanced activity}

Within the framework of professional development courses of mathematics teachers in the field of geometry, when we want to expose teachers to items which represent different levels of thinking we can make another use of the questionnaire. This is done by mixing together the questions about the three topics as well as the questions representing different levels of thinking. The teachers attending the courses can be asked first to answer the questions, then classify them according to the learning topics and finally match the items to the three different levels of thinking. This kind of activity is more difficult and is designed for those versed in geometrical topics. Using the questionnaire when the questions are not in the order presented in Appendix A enables respondents to experience classification of the items and matching them to the levels of thinking. When engaging in the 'mixed questionnaire' activity, the maximum recommended time is up to 60 minutes only. The fundamental assumption is that teachers of this subject possess better knowledge and therefore need less time for responding to the questionnaire. Nevertheless, mixing the questions about the different topics and at different levels might render the activity more difficult; hence a longer response time is required. As already mentioned, it is recommended leaving the same time framework of 60 minutes. This recommendation is supported also by Ben-Menachem \& Sela (2005). The researchers attribute importance to the organisation of the questions by an increasing order of difficulty and in an allocated response time since the element of time affects the identification of the mastery of levels of thinking. If the questionnaire is administered without time limitation, perusal and rereading of certain questions might entail a change of the previous answer. This is due to the fact that by re-checking and re-reading the questions one can find clues which might blur the ability to discern mastery of the levels of thinking.

\section{Examples of questions at the first level}

The questions at the first level include questions of identification and distinction. As mentioned above, at this initial level learners can identify geometric shapes and discern between them according to a drawing. Each of the concepts or the shapes is perceived as 
a whole, as it is seen. At this level learners have not mastered the properties of those shapes.

An example of a question at the first level dealing with the topic of a circle:

Below is a drawing of three circles: $\mathrm{O}, \mathrm{M}$, and $\mathrm{A}$.

Which of the following claims is correct?

a. In circle $\mathrm{A}-\mathrm{MA}$ is a diameter;

b. In circle $\mathrm{O}-\mathrm{KE}$ is a diameter;

c. In circle $\mathrm{A}-\mathrm{MO}$ is a diameter

d. In circle $\mathrm{O}-\mathrm{MO}$ is a diameter;

e. In circle $\mathrm{M}-\mathrm{KE}$ is a diameter.

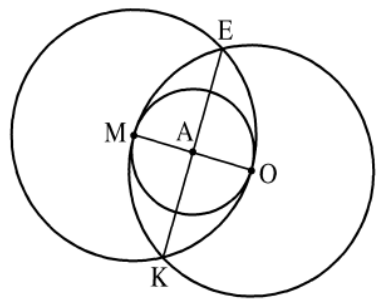

In order to answer the question, learners should focus on each of the circles separately and identify whether the segment indicated in it is indeed a diameter.

The questions at the second level relate to geometric properties of 2-D or 3-D shapes. At this level learners are supposed to identify a certain shape, be aware that it has several properties and check the existence or non-existence of the properties with regards to the shape.

An example of a question at the second level dealing with the topic of solids

Which of the following statements is true for every prism?

a. The lateral surface of the prism consists entirely of triangles.

b. The prism had two parallel bases.

c. The base of the prism is rectangular.

d. The lateral surface of the prism consists of regular polygons.

e. Four faces intersect every vertex of the prism.

The third level includes questions relating to relationships of connection between the various shapes and solids and to drawing conclusions. At this level learners can manipulate the properties as well as derive information about the properties of the shapes based on other properties presented to them.

An example of a question at the third level dealing with the topic of solids:

Which of the following statements is true?

a. If an object has 8 vertices it must be a rectangular parallelepiped.

b. If an object has 8 vertices it must be a cube.

c. If an object has 8 vertices it must be a pyramid.

d. If an object has 8 vertices it must be a regular polyhedron.

e. Statements $\mathrm{a}-\mathrm{d}$ are false. 


\section{Suggestion for encoding the questionnaire for mapping the level of thinking}

Determining the level of thinking in the various topics is done by the weighted scores. Please remember that mastery of a certain level necessitates mastery of each of the previous levels.

Following the development of the questionnaire by Usiskin (1982), the weighted scores were determined on the basis of the criterion according to which at least three out of five correct answers at each level indicates compliance with that level and awards point. Nevertheless, Usiskin argued that the criterion of 'three out of five' is a lenient criterion. Hence, he recommended using the stricter criterion of 'four out of five' (Usiskin, 1982), according to which giving four out of five correct answers at any level indicates compliance with the level and awards points. Identifying the level of thinking in a topic is determined by the way of encoding the answers and weighting the scores, as follows:

\section{a. Way of scoring the answers:}

1. Giving at least three/four ${ }^{1}$ out of five correct answers at the first levels awards one point.

2. Giving at least three/four out of five correct answers at the second levels awards two points.

3. Giving at least three/four out of five correct answers at the third levels awards four points.

\section{b. Way of weighting the scores}

A weighted score is comprised in the following way: complying with the criterion at the first level + complying with the criterion at the second level + complying with the criterion at the third level and so on. If $\mathbf{a}$ is the variable representing compliance with criterion at any level, a can get the values 0 (fails to comply with the criterion) or 1 (complies with the criterion because the learner has given three or four out of five correct answers). In that case the weighted score can be represented in the following way: $\mathbf{a} \cdot \mathbf{1}+\mathbf{a} \cdot \mathbf{2}+\mathbf{a} \cdot \mathbf{4}=$ weighted score.

Hence, the scores range ${ }^{2}$ which relates to mastery of three out of first four levels of thinking in geometry, is between $0-7$ for each topic (triangles and quadrilaterals - the

1 At least four out of five correct answers relate to the strict criterion

2 If we relate also to the fourth level, we have to add also $\mathbf{a} \mathbf{8}$, that is $(\mathbf{1} \mathbf{1 + 1} \mathbf{2 + 1} \mathbf{4 + 1} \mathbf{8})$ and the score range will be $0-15$. Those advocating the existence of five levels have to add also $\mathbf{a}^{\cdot 16}$. In this case the score range is $0-31$ for each topic and the weighted score representing mastery of all five levels in this topic is 31 . 
first topic, circles and proportion - second topic and solids - the third topic) (Patkin, 1990; Sarfaty \& Patkin, 2010).

In light of the above, according to van Hiele theory no learner can be at level $\mathrm{X}$ before having mastered level $\mathrm{X}-1$. That is, learners must be versed in all previous levels of thinking; otherwise they are referred to as 'inconsistent'. The weighted scores facilitate identification of learners' levels of thinking as follows: learners who have not mastered the first level of thinking will get the score of 0 . Learners who have mastered the first level of thinking will get the score of 1. Learners versed in the second level of thinking will get the score of $3(1 \cdot 1+12)$ and learners versed in the third level of thinking will get the score of $7(1 \cdot 1+12+14)$. The other scores represent 'inconsistent' learners in the examined topic.

\section{SUMMARY}

This paper presents a questionnaire which enables the mapping of levels of thinking in geometry associated with three main geometrical topics: triangles and quadrilaterals, circle and solids. The questions relate to the first three levels, namely identification of 2-D and 3-D shapes (first level according to van Hiele); the properties of those shapes (second level according to van Hiele); and the ability to draw conclusions in an informal way (third level according to van Hiele).

Studies conducted in Israel and worldwide which explored the geometrical capability of pre-service teachers illustrate that most participants usually master the first two levels and only a small number among them master the third level (Gutierrez, Jaime \& Fortuny, 1991; Halat \& Sahin, 2008; Sarfaty \& Patkin, 2010). Similarly, Patkin \& Barkai (in press) found that most of the pre- and in-service teachers hold a full matriculation certificate, including in mathematics and some of them studied advanced level mathematics at high school. Nevertheless, they demonstrated only partial mastery according to the van Hiele theory.

Using the Global van Hiele questionnaire might enhance the trend prevalent today which strives to improve and promote geometry studies at mathematics teacher education colleges. The ability to map the levels of thinking of pre-service teachers could facilitate teacher-educators' coping with common errors and misconceptions of pre-service mathematics teachers. Moreover, it might enhance their Curricular Content Knowledge (CCK) and their Pedagogical Content Knowledge (PCK). In addition, they could develop competences and skills required particularly in the topics of solids and circle in which preservice teachers tend to demonstrate lack of mastery and low achievements. It is to be hoped that this will entail additional learning hours and courses focused on these topics, 
training teachers to master the higher levels of thinking in these topics so that they can teach them in the best way.

\section{REFERENCES}

Ben-Menachem, O. \& Sela, L. (2005). Integrating the test in the assessment culture. Eureka 21, 32-36. [Hebrew]

Cohen, N. (2007). Analytical-visual combination in the performance of assignments in space Analysis of thinking processes of pre- and in-service teachers. Ph.D. Thesis. Beer-Sheba, Israel: Ben Gurion University of the Negev. [Hebrew]

Clements, D. H., \& Battista, M. T. (1992). Geometry and spatial reasoning. In: G. Douglas (Ed.). Handbook of research on mathematics teaching and learning, (pp. 420-464), New York: Macmillan.

Crowley, M. L. (1987). Van Hiele Model of the Development of Geometrical Thought. In: M. Montgomery Lindquist, \& A. P. Shulte (Eds.), Learning and Teaching Geometry, K-12, (pp. 116), 1987 Yearbook of the National Council of Teachers of Mathematics (NCTM), Reston, VA.: NCTM, 1987.

Friedlander, A. (1988). Principles in the teaching of Euclidian geometry. In: A. Friedlander (Ed,), Teaching geometry - Collection of sources and activities for methodics lessons (pp. 149-219), Rehovoth: Weizmann Institute of Science, Department of Sciences Teaching. [Hebrew]

Geddes, D.; Fuys, D.; Lovett, J. C. \& Tischler, R. (1982). An Investigation of the Van Hiele Model of Thinking in Geometry Among Adolescents. Project Report, presented at NCTM 1982 Annual Meeting, Toronto, Canada.

Geddes, D.; Fuys, D.; Lovett, J. C. \& Tischler, R. (1985). An investigation of the van Hiele model of thinking in geometry among adolescents. Final report. Research in science education (RISE) program of the National Science_Foundation, Grant no. SED 7920640, Washington, D.C.: National Science Foundation

Guberman, R. (2008). A framework for characterizing the development of arithmetic thinking. In: Proceedings of ICME-11-Topic study group 10, Research and development in the teaching and learning of number systems and arithmetic. Monterrey, Mexico. (pp. 113-121).

Gutierrez, A. (1992). Exploring the links between van Hiele levels and 3-dimensional geometry. Topologie Struct. 18, 31-48. ME 1995a.00083

Gutierrez, A.; Jaime, A. \& Fortuny, J. M., (1991). An alternative paradigm to evaluate the acquisition of the van Hiele levels. J. Res. Math. Educ. 22(3), 237-251. ME 1992a.00854

Halat, E. \& Sahin, O. (2008). Van Hiele levels of pre- and in- service Turkish elementary school teachers and gender related differences in geometry. Math. Educ. 11(1-2), 143-158. ME 2012f.00713 
Hoffer, A. R. (1979). Geometry: a model of the universe. Menlo Park, Calif.: Addison-Wesley. (1981). Geometry is more than a proof. Math. Teacher. 74(1), 11-18. ME 1981x.01699 (1983). Van-Hiele based research. In: R. Lesh \& M.Landau (Eds.), Acquisition of Mathematics Concepts and Processes. New York, NY: Academic Press. ME 1985d.02153

Koester, B. A. (2003). Prisms and pyramids: Constructing three-dimensional models to build understanding. Teach. Child. Math. 9(8), 436-442. ME 2003f.05035

Levi, A. (1969). Computerised summary of test results. Jerusalem, Israel: Ministry of Education and Culture, Curricula Unit. [Hebrew]

Patkin, D. (1990). The utilization of computers: Its influence on individualized learning, pair versus individualistic learning. On the perception and comprehension of concepts in Euclidean geometry at various cognitive levels within high school students. Doctoal dissertation, Tel-Aviv, Israel: Tel-Aviv University. [Hebrew]

(2010). The role of "personal knowledge" in solid geometry among primary school mathematics teachers. J. Korea Soc. Math. Educ. Ser. D 14(3), 263-279.

Patkin, D. \& Levenberg, I. (2004) Geometry - Part II for junior high and high school, (2 ${ }^{\text {nd }}$ ed.). Israel, Holon : Rachgold Press. [Hebrew]

(2010) Geometry - Part I for junior high and high school, (2 $2^{\text {nd }}$ ed.). Published by the authors. [Hebrew]

Patkin, D. \& Sarfaty, Y. (2012). The effect of solid geometry activities of pre-service elementary school mathematics teachers on concepts understanding and mastery of geometric thinking levels. J. Korean Soc. Math. Educ., Ser. D, Res. Math. Educ. 16 (1),.31-50.

Patkin, D., \& Barkai, R. (in press). Geometric Thinking Levels of Pre- and In-Service Mathematics Teachers at Various Levels of their Education. In: D. Patkin \& A. Gazit (Eds.), The Narrative of Mathematics Teachers - Elementary School Mathematics Teachers' Features of Education, Knowledge, Teaching and Personality. Israel, Tel-Aviv, Moffet Institute Press.

Piaget, J. (1969) The intellectual development of the adolescent. In: A. H. Esman (Ed.), The Psychology of Adolescence (1985). NewYork, NY: International Universities Press.

Pyshkalo, A. M. (1968). Geometry in Grades 1-4: Problems in the Formations of Geometric Conceptions in Pupils in the Primary Grades. (Trans. 1981 by Recent East European Mathematical Literature of the University of Chicago, I. Wirszup, Ed.) Moscow: Prosveshchenie Publishing

Reingold, O. (1986). The effect of stimulation means by using the computer as an 'electronic board' by the knowledge and understanding of concepts in formal geometry. M.A. dissertation, Tel Aviv: Tel Aviv University, School of Education. [Hebrew]

Senk, S. L. (1983). Proof-writing Achievement and van Hiele levels among secondary school geometry students. Ph.D. dissertation, Chicago, IL: University of Chicago.

(1985).How well do students write geometry proofs? Mathematics Teacher, 78(6), 448-456. ME 1986x.00184

Senk, S. L. \& Usiskin, Z. (1983). Geometry proof-writing: A new view of differences in mathe- 
matical ability. American Journal of Education 91 (2), 187-201.

Tepper, A. (1986). Effect of colour in computer-aided teaching and its influence on the comprehension of concepts in Euclidian geometry. M.A. dissertation, Tel Aviv: Tel Aviv University, School of Education. [Hebrew]

Teppo, A. (1991). Van Hiele levels of geometric thought revisited. Math. Teacher. 84(3), 210-220. ME 1991g. 37100

Usiskin, Z. (1982). Van Hiele levels and achievement in secondary school geometry. Final report of the Cognitive Development and Achievement in Secondary School Geometry - CDASSG Project. Chicago, IL: University of Chicago. (ERIC Document Reproduction Service No. ED220288).

Van Hiele, P. M. (1959). La pensee de l'enfant et la Geometrie. Bulletin de l'Association des Professeurs de Mathematiques de l'Enseignement Public 198, 199-205.

(1987). Van-Hiele levels, A method to facilitate the finding of levels of thinking in geometry by using the levels in arithmetic. Paper presented at the conference on learning and teaching geometry: Issues for research and practice. Syracuse University.

(1999). Developing geometric thinking through activities that begin with play. Teach. Child. Math. 5(6), 310-316. ME 2000b.01169

Wirszup, I. (1976). Breakthroughs in the psychology of learning and teaching geometry. In: J. I. Martin \& D. A. Bradbard (Eds.), Space and geometry: Papers from a research workshop. (pp. 75-97). Columbus, Ohio: ERIC Center for Science, Mathematics and Environment Education. 


\section{APPENDIX \\ GLOBAL VAN-HIELE QUESTIONNAIRE}

Read each question carefully and choose the correct ansewr:

1. Which of the following figures are triangles?
a. None of the figures.
b. V only.
c. W only.
d. W and X only.
e. V and W only.

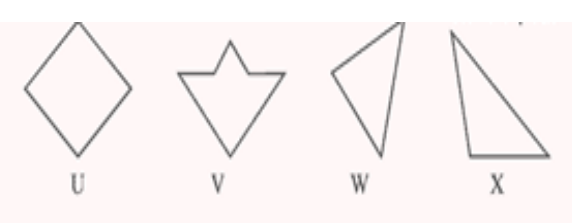

2. Which of the following figures are rectangles?
a. S only.
b. T only.
c. $\quad$ S and T only.
d. S and U only.
e. All the figures are rectangles.

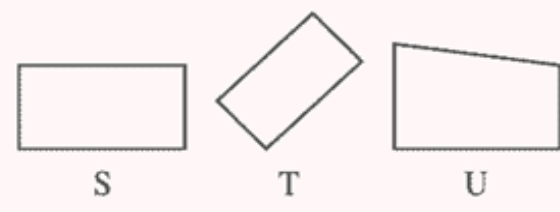

3. Which of the following figures are squares?
a. S only.
b. T only.
c. S and T only.
d. S and U only.
e. All the figures are squares.

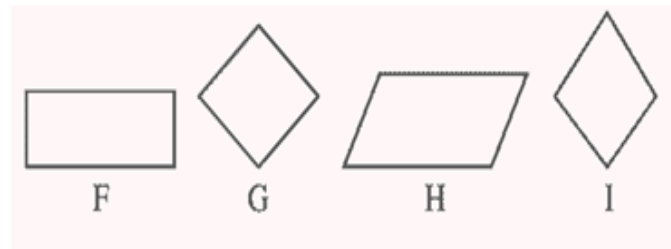

4. Which of the following figures are parallelograms?
a. J only.
b. L only.
c. J and T only.
d. None of the figures.
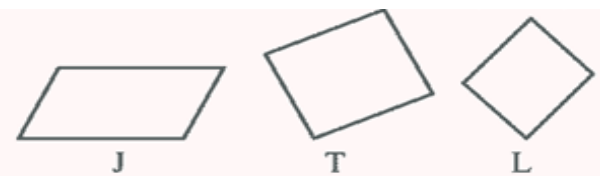
e. All the figures are parallelograms. 
5. Which of the following figures are rhombuses?
a. K only.
b. L only.
c. $\mathrm{M}$ only.
d. L and M only.
e. All the following figures are rhombuses.

6. Which of the following segments are chords in circle $\mathbf{O}$ ?
a. $\mathrm{AB}$ only.
b. OE only.
c. $\mathrm{AB}, \mathrm{DF}, \mathrm{CD}$ only.
d. $\mathrm{AB}, \mathrm{CD}, \mathrm{AF}, \mathrm{FD}$.
e. $\mathrm{AB}, \mathrm{OF}, \mathrm{OE}, \mathrm{ED}, \mathrm{CD}$.

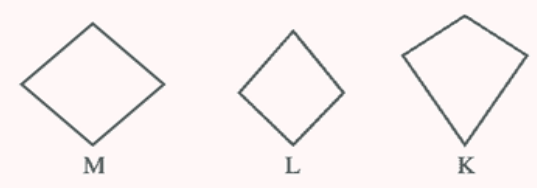

7. Which drawings present inscribed triangles in a circle?

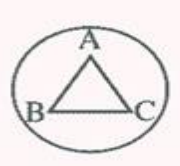

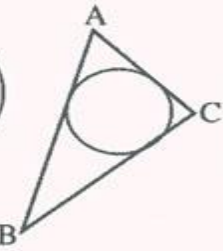

b

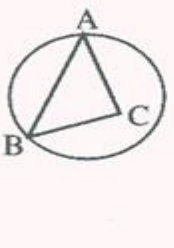

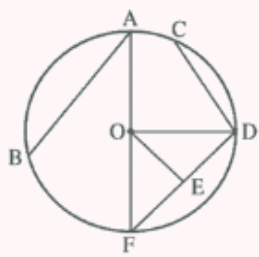

8. Which drawings present tangent circles?
a. B and D only.
b. C and D only.
c. C only

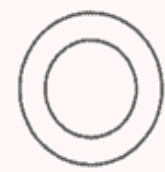
d. B and C only.
A
e. None of the drawings.

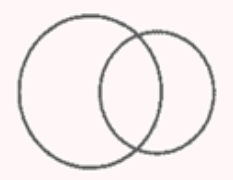

B

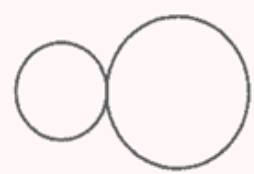

C

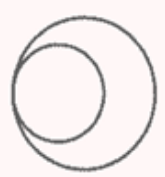

$\mathrm{D}$ 
9. Below is a drawing of three circles: $\mathrm{O}, \mathrm{M}$ and $\mathrm{A}$.

Which of the following claims is correct?
a. In circle $\mathrm{A}-\mathrm{MA}$ is a diameter;
b. In circle $\mathrm{O}-\mathrm{KE}$ is a diameter;
c. In circle $\mathrm{A}-\mathrm{MO}$ is a diameter
d. In circle $\mathrm{O}-\mathrm{MO}$ is a diameter;
e. In circle $\mathrm{M}-\mathrm{KE}$ is a diameter.

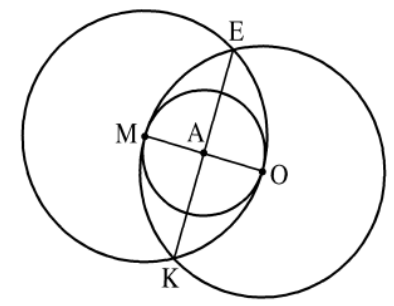

10. Which drawings present sectors of circles?

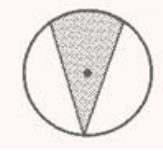

a

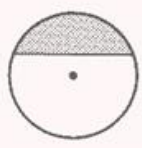

b

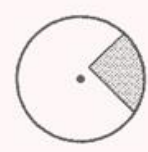

c

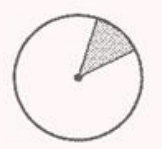

d

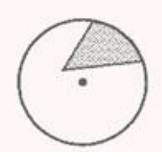

e

11. Circle the prisms among the following objects

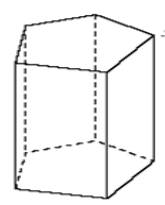

a

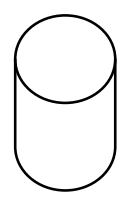

b

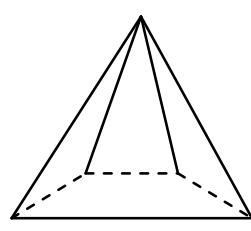

c

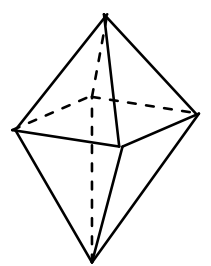

d

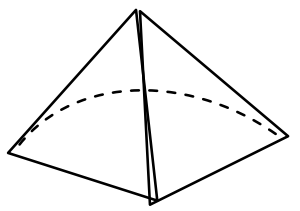

e

12. Circle the cone-shaped object

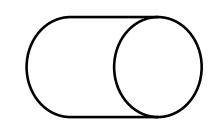

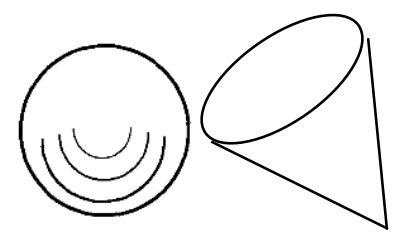

b

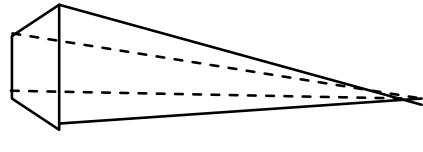

d

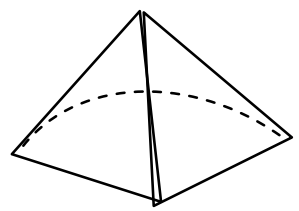

e

13. Circle the polyhedrons among the following objects

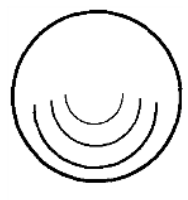

a

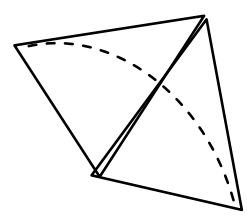

b

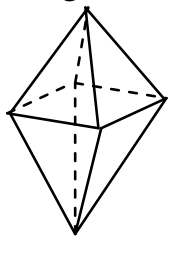

c

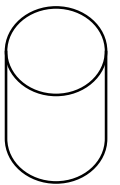

d

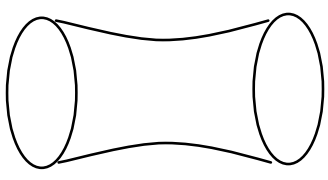

e 
14. Among the following objects, circle the cylinder-shaped ones

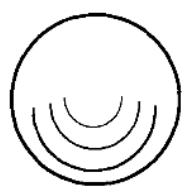

$\mathrm{a}$

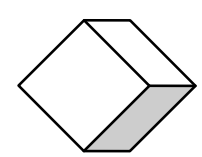

b

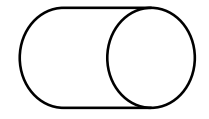

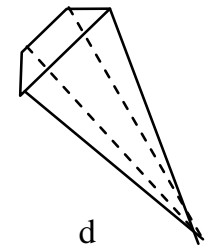

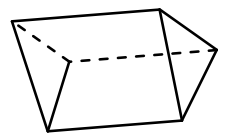

e

15. Which of the following figures are pyramids?

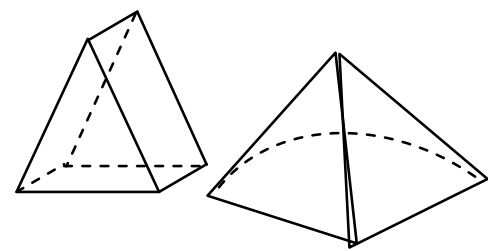

a

b

C

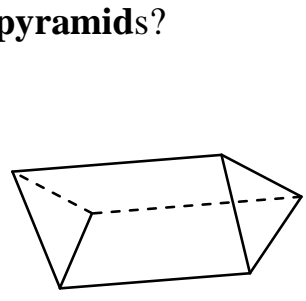

d

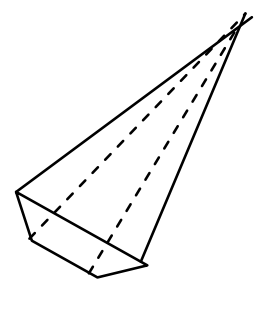

e

16. $\mathrm{PQRS}$ is a square.

Which of the following statements is always true?

a. PR and RS have the same length.

b. QS and PR are perpendicular to each other.

c. PS and QR are perpendicular to each other.

d. PS and QS have the same length.

e. The angle $\mathrm{Q}$ is larger than angle $\mathrm{R}$.

17. HIJK is a rectangle.

Which of the following statements is always false?

a. All the angles are right angles.

b. The diagonals are perpendicular to each other.

c. The opposite angles have the same measure.

d. The diagonals have the same length.

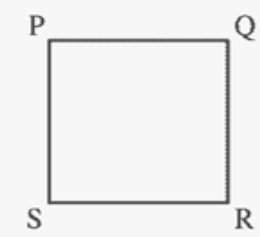

e. The opposite sides have the same length.

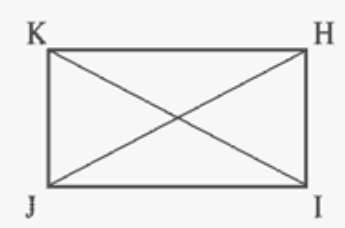


18. $\mathrm{ABCD}$ is a rhombus.

Which of the following statements is always false?

a. The diagonals have the same length

b. Each diagonal bisects two angles of the rhombus.

c. The diagonals are perpendicular to each other.

d. The opposite angles have the same measure.

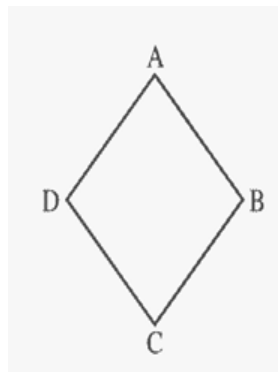

e. All the sides are equal.

19. DEF is an isosceles triangle.

Which of the following statements is always true?

a. The three sides have the same length.

b. One side must have twice the length of another side.

c. There must be at least two angles with the same measure.

d. The three angles must have the same measure.

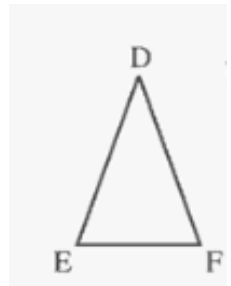

e. The base angle is larger than the vertex angle.

20. ABCD is a parallelogram.

Which of the following statements is always true?

a. The four sides have the same length.

b. The two diagonals are equal.

c. The diagonals bisect the angles.

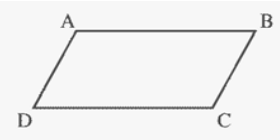

d. The opposite angles have the same measure.

e. The diagonals are perpendicular to each other.

21 . Which of the 5 following statements is not true?

a. Every inscribed trapezium in a circle is an isosceles trapezium.

b. In every inscribed quadrangle in a circle, the sum of the angles is $180^{\circ}$.

c. If a square is inscribed in a circle, the diagonal is the diameter of the circle.

d. If a rectangle is inscribed in a circle, the diagonal is the diameter of the circle.

e. Every quadrangle can be inscribed in a circle. 
22. Below is a circle $\mathrm{O}$.

Which of the 5 following statements is not true?
a. $\Varangle \alpha<\Varangle \beta$
b. $\Varangle \alpha=\Varangle \frac{1}{2} \beta$
c. $\Varangle \alpha=2 \Varangle \beta$
d. $\Varangle \beta>2 \Varangle \alpha$
e. $\Varangle \alpha+\Varangle \beta=300^{0}$

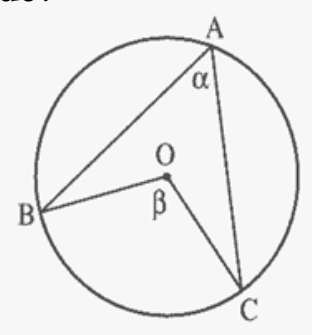

23. Below are a circle $\mathrm{O}$ and two intersecting chords $\mathrm{AB}$ and $\mathrm{CD}$ whose length is equal. Which of the following statements is not true?

a. The arcs of these subtending chords have the same length.

b. The central angles which subtend these arcs are equal.

c. The distance of each chord from the centre is the same.

d. The inscribed angles which subtend these arcs are equal.

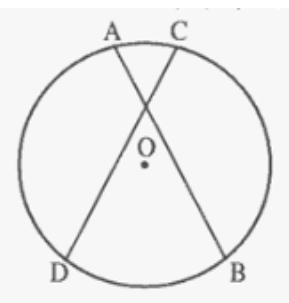

e. The chords are equal; therefore they are perpendicular to each other.

24. Which of the following statements is true?

a. Two diameters in the circle are intersecting at one point: the center of the circle.

b. Two diameters in the circle are always perpendicular to each other.

c. Two diameters in the circle intersect at a point on the circle.

d. Two diameters in the circle can be parallel.

e. In every circle there are only two diameters in the circle.

25. Circles $\mathrm{O}_{1}$ and circle $\mathrm{O}_{2}$ are not equal, and intersect at points $\mathrm{A}$ and $\mathrm{B}$.

The quadrangle $\mathrm{AO}_{1} \mathrm{BO}_{2}$ is:
a. A square.
b. A rhombus.
c. A kite.
d. A parallelogram.
e. You never know.

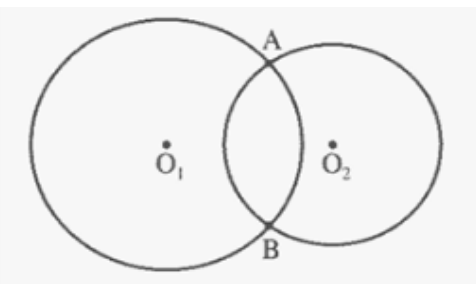


26. Which of the following statements is always true?

a. If an object has two bases then it must be a rectangular parallelepiped.

b. If an object has two bases then it must be a polyhedron.

c. If an object has two bases then it must be a cylinder.

d. If an object has two bases then it must be a regular polyhedron.

e. Statements $a-d$ are false.

27. Which of the following statements is true for every cylinder?

a. The bases of a cylinder are circular.

b. The bases of the cylinder are congruent and parallel squares.

c. The bases of the cylinder consist of regular polygons.

d. The bases of the cylinder are pentagons.

e. The bases of the cylinder are triangles.

28. Which of the following statements is true for every regular polyhedron?

a. In a polyhedron all faces are congruent.

b. All polyhedrons have pairs of parallel faces.

c. A polyhedron does not have curved surfaces.

d. Each vertex in a polyhedron intersects a number of other faces.

e. Statements a-d are true.

29. A cube has:
a. 12 faces,
b. 4 faces,
c. 6 faces,
d. 8 faces,
e. 2 faces

30. Which of the following statements is true for every prism?

a. The lateral surface of the prism consists entirely of triangles.

b. The prism had two parallel bases.

c. The base of the prism is rectangular.

d. The lateral surface of the prism consists of regular polygons.

e. Four faces intersect every vertex of the prism. 
31. Which of the following statements is true?

a. If a geometric figure is a rectangle, then it is a triangle.

b. If a geometric figure is not a rectangle, then it is a triangle.

c. If a geometric figure is a triangle, then it is a rectangle.

d. It is impossible for a geometric figure to be a rectangle and a triangle at the same time.

e. Statements $\mathrm{a}-\mathrm{d}$ are false.

32. Which of the following statements is true?

a. If a geometric figure is a rhombus, it is a parallelogram.

b. If a geometric figure is a parallelogram, it is a rhombus.

c. If a geometric figure is not a rhombus, it is a parallelogram.

d. If a geometric figure is not a rhombus, it is not a parallelogram.

e. Statements a $-\mathrm{d}$ are false.

33. Which of the following statements is true?

a. All the properties of rectangles are properties of all squares.

b. All properties of squares are properties of all rectangles.

c. All properties of rhombuses are properties of all parallelograms.

d. All properties of squares are properties of all parallelograms.

e. Statements $\mathrm{a}-\mathrm{d}$ are false.

34. Which of the following properties is a property of all the rectangles, but not a property of all the parallelograms?

a. The opposite sides are equal.

b. The diagonals have the same length.

c. The opposite sides are parallel.

d. The opposite angles are equal.

e. None of the statements $\mathrm{a}-\mathrm{d}$ is true 
35. Which of the following properties is a property of all the rhombuses, but not a property of all the parallelograms?

a. The opposite sides are parallel.

b. The adjacent sides have the same length.

c. The opposite angles are parallel.

d. The diagonals bisect each other.

e. Statements $\mathrm{a}-\mathrm{d}$ are false.

36. Which of the following statements is true?

a. If two triangles are similar, they are congruent.

b. If two triangles are equal in one angle and one side, they are similar triangles.

c. If two angles of two triangles are proportional, they are similar triangles.

d. If two triangles are congruent, they are always similar.

e. If two triangles have two equal sides in both of them, they are similar triangles.

37. Which of the following statements is true?

a. Every central angle is also an interior angle.

b. Every central angle is also an inscribed angle.

c. Every inscribed angle is also a central angle.

d. Every interior angle is also a central angle.

e. Statements a $-\mathrm{d}$ are false.

38. Which of the following statements is true?

a. If a polygon is inscribed in a circle, then it is a triangle.

b. If a polygon can't be inscribed in a circle, then it is a triangle.

c. If a polygon is a triangle, then the polygon is inscribed in a circle.

d. If a polygon is not a triangle, then the polygon is inscribed in a circle

e. Statements a $-\mathrm{d}$ are false. 
39. Which of the following statements always applies to an isosceles triangle but not to all the triangles?

a. The midline is parallel to one of the three sides of the triangle.

b. The midline is equal to half of one of the three sides of the triangle.

c. The midline creates a triangle which is similar to the original one.

d. The midline creates an isosceles trapezium.

e. The midline creates a trapezium.

40. Which of the following properties is a property of all the regular polygons, but not a property of all the convex polygons?

a. The sum of all the interior angles is $180(n-2)$.

b. The number of the sides is the number of the angles.

c. The area of a polygon is equal to the total areas of all partial polygons which comprise the polygon.

d. The sum of all the exterior angles is $360^{\circ}$.

e. The polygons can be inscribed into a circle.

41. All pyramids have in common:

a. All pyramids have a triangular-shaped base.

b. The lateral surface is constructed of triangles.

c. The base is a quadrangle and the lateral surface is comprised of triangles.

d. All faces of the pyramid are triangles.

e. Statements $\mathrm{a}-\mathrm{d}$ are false.

42. Which of the following statements is true?

a. If an object is a polyhedron then it is also a prism.

b. If an object is a prism then it is also a polyhedron.

c. If an object is not a polyhedron, then it is a prism.

d. If an object is not a prism, it is not a polyhedron.

e. If an object is a prism, it is not a polyhedron. 
43. Which of the following statements is true?

a. If an object has 8 vertices it must be a rectangular parallelepiped.

b. If an object has 8 vertices it must be a cube.

c. If an object has 8 vertices it must be a pyramid.

d. If an object has 8 vertices it must be a regular polyhedron.

e. Statements $a-d$ are false.

44. Which of the following statements is true?

a. If an object is a regular polyhedron, it is also a cube.

b. If an object is a cube, it is also a regular polyhedron.

c. If an object is not a regular polyhedron, it is a cube.

d. If an object is not a cube, it is not a regular polyhedron.

e. Statements $a-d$ are true.

45. Which of the following statements is not true for a prism?

a. The prism has two congruent and parallel bases.

b. The lateral surface of the prism is comprised of rectangles or parallelograms.

c. All the faces of the prism are rectangles or parallelograms.

d. The prism is a 3-dimensional object.

e. All the faces of the prism are polygons. 